\title{
Ácido salicílico atenua o efeito do estresse hídrico na germinação e crescimento inicial de plântulas de Cereus jamacaru DC
}

Salicylic acid as an attenuator of water stress in germination and initial growth of seedlings of Cereus jamacaru DC

\author{
J. S. Nóbrega ${ }^{1 *}$; R. G. da S. Nascimento ${ }^{1}$; R. T. da Silva ${ }^{1}$; F. R. A. Figueiredo ${ }^{2}$; A. \\ C. Bezerra ${ }^{1}$; M. de F. de Q. Lopes ${ }^{1}$; E. U. Alves ${ }^{1}$; R. de L. A. Bruno ${ }^{1}$ \\ ${ }^{1}$ Universidade Federal da Paraíba, Centro de Ciências Agrárias, 58397-000, Areia-PB, Brasil \\ ${ }^{2}$ Universidade Federal Rural do Semi-Árido, 59625-900, Mossoró-RN, Brasil \\ *jacksonnobrega@hotmail.com \\ (Recebido em 21 de dezembro de 2020, aceito em 11 de abril de 2021)
}

\begin{abstract}
A escassez hídrica é um problema para a produção agrícola nas regiões semiáridas, de forma que torna-se necessário estudar seus efeitos, assim como medidas para atenuar tais danos na germinação e crescimento inicial das plântulas. Objetivou-se avaliar o ácido salicílico (AS) como atenuador do estresse durante a germinação de sementes e crescimento inicial das plântulas de Cereus jamacaru. O experimento foi conduzido em delineamento inteiramente casualizado em esquema fatorial 5 x 5 , sendo cinco potenciais osmóticos $(0,0 ;-0,2 ;-0,4 ;-0,8$ e -1,2MPa) induzidos por polietilenoglicol (PEG 6000) e cinco doses de AS $\left(0,0 ; 0,29 ; 1,0 ; 1,71\right.$ e $\left.2,0 \mathrm{mM} \mathrm{L}^{-1}\right)$. As avaliações realizadas foram: porcentagem de germinação, primeira contagem, índice de velocidade, tempo médio e velocidade média de germinação, comprimento, massa fresca e seca de plântulas. O estresse hídrico induzido por soluções de PEG 6000 reduz a qualidade e o vigor das sementes de $C$. jamacaru. A embebição de sementes com AS atenua o efeito déficit hídrico, sendo a dose de $1,71 \mathrm{mM} \mathrm{L}^{-1}$ a mais eficiente para reduzir os danos promovidos pelo estresse hídrico sobre a germinação das sementes de $C$. jamacaru.
\end{abstract}

Palavras-chave: Caatinga, fitohormônio, embebição de sementes.

Water scarcity is a problem for plant growth in semiarid regions, so it is necessary to study its effects, as well as measures to mitigate such damage in germination and initial seedling growth. The objective of this study was to evaluate salicylic acid (AS) as a stress attenuator during seed germination and initial growth of Cereus jamacaru seedlings. The experiment was conducted in a completely randomized design in a $5 \times 5$ factorial scheme, with five potential osmotics $(0.0 ;-0.2 ;-0.4 ;-0.8$ and $-1.2 \mathrm{MPa})$ induced by polyethylene glycol (PEG 6000) and five doses of AS $(0.0 ; 0.29 ; 1.0 ; 1.71$ and $2.0 \mathrm{mM} \mathrm{L}-1)$. The evaluations carried out were: germination percentage, first count, speed index, average time and average germination speed, length, fresh and dry seedling mass. The water stress induced by PEG 6000 solutions reduces the quality and vigor of $C$. jamacaru seeds. Soaking of seeds with AS attenuates the water deficit effect, with the dose of $1.71 \mathrm{mM} \mathrm{L}^{-1}$ being the most efficient to reduce the damage caused by water stress on the germination of $C$. jamacaru seeds.

Keywords: Caatinga, phytohormone, seed soaking.

\section{INTRODUÇÃO}

O mandacaru (Cereus jamacaru DC) é uma espécie pertencente à família das Cactáceas, com características de tolerância a condições edafoclimáticas das regiões semiáridas, possuindo atributos morfofisiológicos que possibilitam resistir pelos longos períodos de ausência de chuvas que ocorre no Nordeste brasileiro [1], no entanto, estudos demonstraram a sensibilidade ao estresse hídrico durante as fases de germinação e crescimento inicial [2]. A espécie é de ampla distribuição nas regiões áridas e semiáridas, servindo como recurso forrageiro para alimentação de animais [3]. Além disso é utilizada na medicina tradicional para o tratamento de úlceras e doenças do trato respiratório devido ao elevado conteúdo de compostos bioativos com potencial de uso fitoterápico [4]. 
A disponibilidade de água durante o período de germinação e estabelecimento da plântula é um dos principais fatores que compromete o processo, especialmente em locais em que o aporte de água é limitado [5, 6]. A baixa disponibilidade de água pode comprometer todo o processo germinativo e o vigor da semente, afetando a porcentagem, velocidade e a uniformidade da germinação [7]. A água atua desencadeando diversos processos que ocorre durante a germinação, como na hidratação dos tecidos, aumento da atividade respiratória, hidrólise de proteínas e atividades metabólicas que irão servir como fonte de nutrientes e energia para a retomada do crescimento do eixo embrionário [8].

Para se induzir o estresse hídrico utiliza-se soluções de polietilenoglicol (PEG 6000), o qual tende a reduzir a disponibilidade hídrica para as sementes, proporcionando o ajuste osmótico. A redução do potencial hídrico reduz a capacidade de absorção de água pela semente [9], proporcionando a lenta embebição e induzindo a resistência durante a ativação do metabolismo da germinação [10].

O uso de fitohormônios é crescente como estratégia para induzir maior tolerância a condições de estresses abióticos, tais como o ácido salicílico (AS) [11, 12], uma vez que estes podem atuar na sinalização e expressão de genes que atuam ativando mecanismos de defesa vegetal, aumentando a tolerância às condições de estresse [13].

A embebição das sementes com AS é uma técnica que proporciona maior tolerância durante a germinação e estabelecimento inicial da planta, promovendo a sinalização e expressão de genes envolvidos na homeostase induzido pelo estresse [12]. Fato constatado em feijão (Vigna unguiculata Walp.) sob déficit hídrico [14], em alfazema brava [Mesosphaerum suaveolens (L.) Kuntze] em condições de estresse salino [12].

No entanto, poucas são as informações sobre o uso da embebição de sementes com AS em espécies florestais nativas de regiões semiáridas como o Nordeste brasileiro. Assim, propormos o uso da técnica visando estabelecer melhores condições para que essas espécies consigam tolerar o efeito da escassez hídrica, especialmente na fase de germinação e estabelecimento inicial das plântulas. O objetivo foi avaliar o efeito da embebição de sementes em diferentes doses de ácido salicílico na mitigação do déficit hídrico na germinação e qualidade de sementes de Cereus jamacaru DC.

\section{MATERIAL E MÉTODOS}

A pesquisa foi conduzida no Laboratório de Análise de Sementes (LAS), pertencente ao Centro de Ciências Agrárias, da Universidade Federal da Paraíba, Areia, Paraíba, Brasil. A cidade está situada nas coordenadas geográficas $6^{\circ} 57^{\prime} 42^{\prime \prime} \mathrm{S} ; 35^{\circ} 41^{\prime} 43^{\prime \prime} \mathrm{O}$ e altitude de 573 metros.

As sementes de $C$. jamacaru foram obtidas de frutos completamente maduros, colhidos de plantas sadias e localizadas no município de Arcoverde ( $\left.8^{\circ} 25^{\prime} 08^{\prime \prime} \mathrm{S} ; 37^{\circ} 03^{\prime} 14^{\prime \prime} \mathrm{O}\right)$, Pernambuco, com altitude de $663 \mathrm{~m}$ e de clima do tipo BShs', semiárido quente segundo a classificação de Köppen, com chuvas de outono-inverno, temperaturas médias variando entre $12{ }^{\circ} \mathrm{C}$ e $25{ }^{\circ} \mathrm{C}$ e precipitação pluviométrica média anual de $653 \mathrm{~mm}$. Após a colheita, os frutos foram encaminhados ao LAS onde realizou-se a retirada manual das sementes, posterior lavagem em água corrente $\mathrm{e}$ secagem em ambiente de laboratório sobre folhas de papel toalha pelo período de sete dias.

As sementes foram submetidas a potenciais osmóticos de 0,$0 ;-0,2 ;-0,4 ;-0,8$ e $-1,2 \mathrm{MPa}$, induzidos por solução aquosa de polietileno glicol [PEG 6000 - Neon®], cujas soluções foram preparadas conforme Villela et al. (1991) [15].

O ácido salicílico [Cód. 1206 - Dinâmica ${ }^{\circledR}$ ] para obtenção das concentrações de 0,$0 ; 0,29 ; 1,0$; 1,71 e $2,0 \mathrm{mM} \mathrm{L}^{-1}$ foi diluído em $200 \mathrm{~mL}$ água destilada aquecida a $75^{\circ} \mathrm{C}$, onde as sementes foram postas para embeber pelo período de oito horas em recipientes plásticos cobertos por papel alumínio e deixados em temperatura e umidade relativa do ambiente. Posteriormente, as sementes foram submetidas à lavagem com água destilada para a retirada do excesso do ácido.

Para o teste de germinação, as sementes foram dispostas em caixas de acrílico de 11 x 11 x 3 $\mathrm{cm}$, com tampa, do tipo gerbox, utilizando-se como substrato duas folhas de papel mata borrão umedecidas com as soluções de PEG 6000 ajustadas para o potencial osmótico a ser testado, na quantidade equivalente a 2,5 vezes a massa do papel seco. As caixas foram vedadas com papel filme e acondicionadas em câmaras de germinação do tipo Biological Oxygen Demand (B.O.D.), a temperatura de $30^{\circ} \mathrm{C}$ e fotoperíodo de $8 / 16$ horas de luz e escuro, respectivamente. 
Para a caracterização do efeito do estresse hídrico e das concentrações de ácido salicílico, foram avaliadas a germinação a partir da contagem do número de sementes germinadas do $4^{\circ}$ ao $15^{\circ}$ dia após a instalação do experimento. O critério adotado foi plântulas que haviam emitido a raiz primária e os primórdios foliares [16]. A primeira contagem de germinação foi estabelecida por meio do número de sementes germinadas no $4^{\circ}$ dia após a instalação do teste germinação, sendo os resultados expressos em porcentagem de plântulas normais germinadas.

O índice de velocidade de germinação foi estabelecido a partir de contagens diárias do número de sementes germinadas, calculando-se os resultados pela fórmula proposta por Maguire (1962) [17]. O tempo médio de germinação foi obtido por meio de contagens diárias do número de sementes germinadas, com resultados estabelecidos conforme fórmula proposta por Labouriau (1983) [18]. A velocidade média de germinação foi determinada seguindo a fórmula $V=1 / t$, em que $t$ representa o tempo médio de germinação.

O comprimento de plântulas foi determinado ao $15^{\circ}$ dia após a semeadura, medindo-se as mesmas com o auxílio de régua graduada $\mathrm{em} \mathrm{cm}$; a massa fresca foi obtida a partir da pesagem das plântulas em balança analítica de precisão de $0,001 \mathrm{~g}$. Posteriormente, determinou-se a massa seca das plântulas, acondicionando-as em sacos de papel Kraft e colocando-as para secar em estufa de circulação forçada de ar a $65{ }^{\circ} \mathrm{C}$ até atingirem o peso constante, seguido de pesagem em balança analítica de precisão.

O delineamento estatístico foi o inteiramente casualizado em esquema fatorial $5 \times 5$, sendo cinco potenciais osmóticos e cinco concentrações de ácido salicílico, com quatro repetições de 50 sementes. Os dados obtidos foram submetidos à análise de variância pelo teste $\mathrm{F}$, aplicando-se nos casos de significância a análise de regressão, cujo programa estatístico utilizado foi o Sisvar® [19].

\section{RESULTADOS E DISCUSSÃO}

De acordo com a análise de variância, constatou-se efeito significativo para interação entre os fatores potenciais osmóticos e concentrações de AS para a porcentagem, primeira contagem, índice de velocidade, tempo médio e velocidade de germinação e para comprimento de plântulas. Quanto a massa fresca de plântulas houve efeito isolado para os potenciais osmóticos, enquanto que a massa seca não sofreu influência dos tratamentos (Tabela 1).

Tabela 1: Resumo da análise de variância para a porcentagem de germinação $(G \%)$, primeira contagem de germinação (PCG), índice de velocidade de germinação (IVG), tempo médio de germinação (TMG), velocidade média de germinação (VMG) e comprimento de plântula (CPL), massa fresca de plântulas (MFP) e massa seca de plântulas (MSP) de C. jamacaru submetida a diferentes potenciais osmóticos e concentrações de ácido salicílico.

\begin{tabular}{cccccccccc}
\hline Fontes de & \multirow{2}{*}{ GL } & \multicolumn{8}{c}{ Quadrados médios } \\
\cline { 3 - 10 } variação & & G\% & PCG & IVG & TMG & VMG & CPL & MFP & MSP \\
\hline Potenciais & 4 & $243,4^{* *}$ & $892,1^{* *}$ & $3,35^{* *}$ & $4,88^{* *}$ & $0,0031^{* * *}$ & $0,027^{\text {ns }}$ & $0,012^{*}$ & $0,00032^{\text {ns }}$ \\
Concentrações & 4 & $84,89^{* *}$ & $1047,1^{* *}$ & $1,44^{* *}$ & $2,28^{* *}$ & $0,0016^{* *}$ & $0,065^{\text {ns }}$ & $0,010^{\text {ns }}$ & $0,00027^{\text {ns }}$ \\
P x D & 16 & $77,45^{* *}$ & $740,8^{* *}$ & $1,15^{* *}$ & $2,17^{* *}$ & $0,0014^{* * *}$ & $0,085^{*}$ & $0,005^{\text {ns }}$ & $0,00025^{\text {ns }}$ \\
Resíduo & 72 & 13,25 & 119,08 & 0,15 & 0,36 & 0,0002 & 0,047 & 0,0044 & 0,00022 \\
\hline Média & & 89,7 & 69,9 & 4,40 & 6,14 & 0,16 & 1,59 & 0,55 & 0,019 \\
\hline CV $(\%)$ & & 4,06 & 15,6 & 8,92 & 9,88 & 9,75 & 13,51 & 12,02 & 75,5 \\
\hline
\end{tabular}

** e * significativo a 1 e $5 \%$ de probabilidade; ${ }^{\text {ns }}$ não significativo pelo teste $\mathrm{F}$.

A embebição com AS nas diferentes concentrações exerceu influência positiva sobre a porcentagem de sementes germinadas, ocorrendo o máximo incremento (98\%) na dose de 2,0 $\mathrm{mM}$ $\mathrm{L}^{-1}$ de AS nas sementes submetidas ao tratamento controle de 0,0 MPa (Figura 1A). No entanto, cabe destacar o efeito promovido pela dose de $1,71 \mathrm{mM} \mathrm{L}^{-1}$ de AS que aumentou gradativamente a germinação das sementes, mesmo aquelas que foram submetidas ao menor potencial osmótico ($1,2 \mathrm{MPa}$ ), promovendo um incremento na germinação de $11 \%$ ao comparar com as médias obtidas pelo menor e maior potencial osmótico. Possivelmente, a interação entre o AS e o PEG induziu a ativação do sistema de defesa vegetal, proporcionando aumento da germinação mesmo com a 
redução da disponibilidade de água para a semente. Isto em virtude do condicionamento de sementes atuar regulando positivamente a expressão de genes e proteínas envolvidas na divisão celular, proporcionando alterações na organização da parede celular e de membranas dos tecidos internos em repostas ao déficit hídrico [20].

- $0 \bullet 0,29 \bullet 1 \square 1,71 \Delta 2$

A

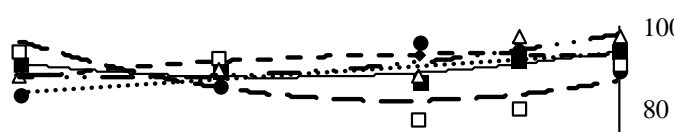

$y=93,9788-18,3865 x+13,2942 * x^{2} R^{2}=0,72$

$\mathrm{y} \bullet=91,1147-6,7974 * x \quad \mathrm{R}^{2}=0,61$

$y \bullet=92,6471+4,4136 x-7,3294 * x^{2} \quad R^{2}=0,65$

$\mathrm{y} \square=86,8923-22,3553 \mathrm{x}+25,2465 * * \mathrm{x}^{2} \quad \mathrm{R}^{2}=0,57$

y $\Delta=98,1335-21,7457 \mathrm{x}+11,3033 * * \mathrm{x}^{2} \quad \mathrm{R}^{2}=0,77$

$-1,2$

$-0,8$

$-0,4$

Potencial osmótico (MPa)

100

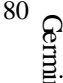

60

$40 \stackrel{0}{3}$

20

0
ロ $0,29 \bullet 1 \square 1,71 \Delta 2$

B

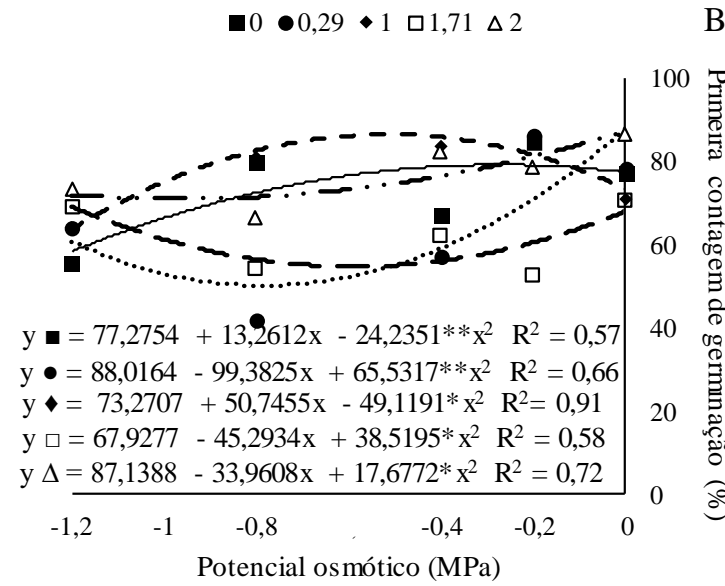

— $0 \bullet 0,29 \bullet 1$ 口 $1,71 \Delta 2$

$\mathrm{C}$

- $0 \bullet 0,29 \bullet 1$ 口 $1,71 \Delta 2$

D
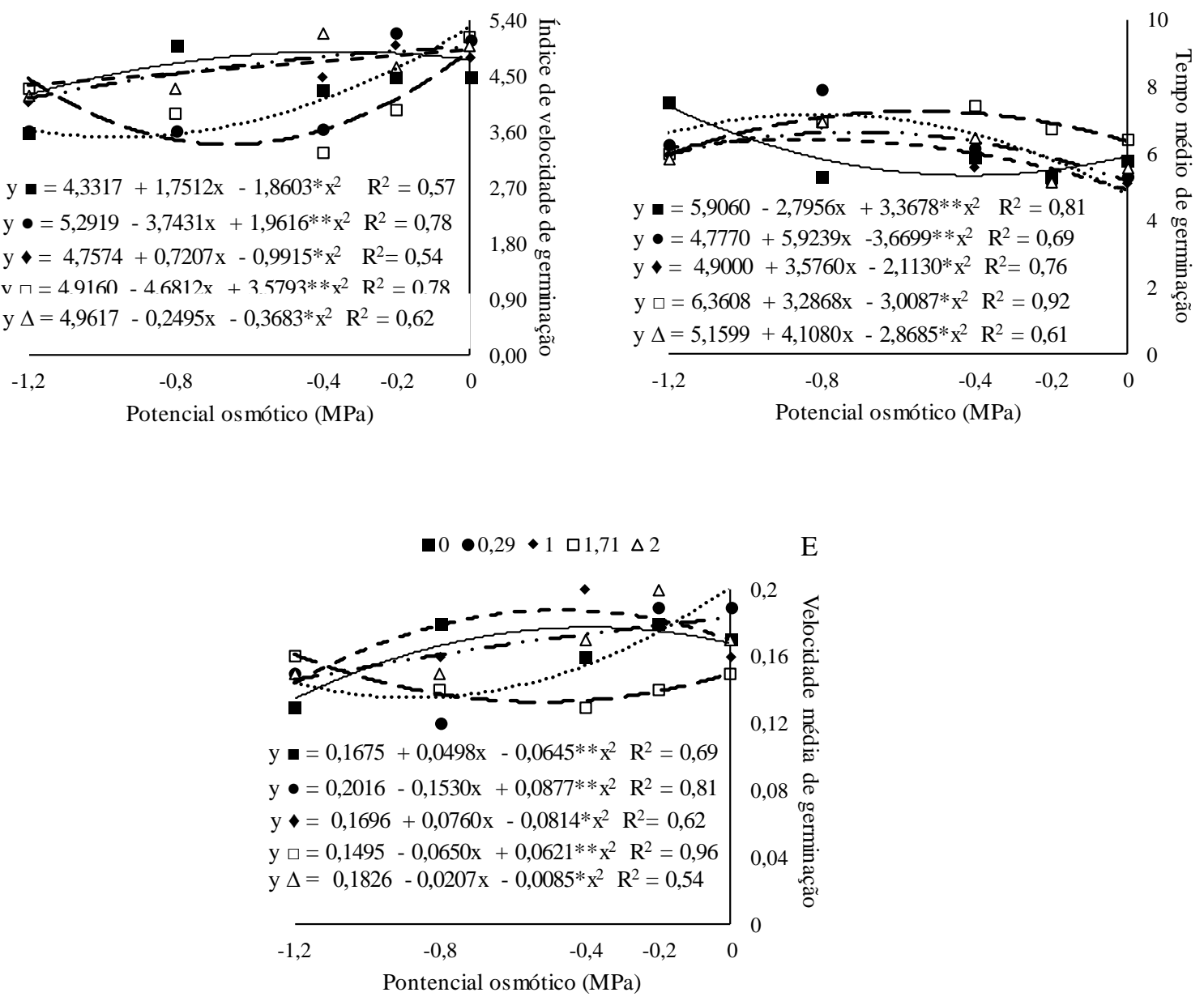

Figura 1: Porcentagem de germinação $(A)$, primeira contagem de germinação $(B)$, indice de velocidade de germinação $(C)$, tempo médio de germinação $(D)$ e velocidade média de germinação $(E)$ de $\mathrm{C}$. jamacaru submetida a diferentes potenciais osmóticos e concentrações de ácido salicílico. 
De modo semelhante à germinação, foi constatado os valores da primeira contagem com o maior valor (87\%) na concentração de $2,0 \mathrm{mM} \mathrm{L}^{-1}$ de AS e no potencial osmótico de $0,0 \mathrm{MPa}$ (Figura 1B). Cabe salientar que a dose de $1,71 \mathrm{mM} \mathrm{L}^{-1}$ de AS foi a que mais atenuou os danos promovidos pelo déficit hídrico durante a germinação, ocorrendo a maior porcentagem de sementes germinadas (69\%) no primeiro dia de contagem no menor potencial matricial (-1,2 MPa) (Figura 1B).

$\mathrm{O}$ aumento gradativo promovido pela dose de $1,71 \mathrm{mM} \mathrm{L}^{-1}$ de AS na porcentagem inicial e final de germinação é um indicativo da sua ação exercida, reduzindo os danos promovidos pelo estresse hídrico aos tecidos internos da semente, resultando no aumento da capacidade de germinação da semente mesmo em condições adversas. A embebição de sementes com AS estimula a produção de metabólitos, induzindo a alterações bioquímicas envolvidas no processo de germinação, dentre elas, a hidrólise de proteínas e ativação de enzimas que regulam a fase inicial do processo germinativo [21, 22].

A indução de resistência a condições de estresse promovida pela embebição de sementes com ácido salicílico foi relatada por outros autores, como em melão (Cucumis melo L.) por Nóbrega et al. (2018) [23] em condições salinas. Araújo et al. (2018) [14] obtiveram aumento na germinação de feijão-caupi (Vigna unguiculata L. Walp) em condições de déficit hídrico induzido. Silva et al. (2019) [24] com a dose de $50 \mu \mathrm{M}$ de ácido salicílico obtiveram aumento na germinação e no vigor de sementes de cebola (Allium cepa L.) sob estresse salino e hídrico.

O vigor das sementes, avaliado pelo índice de velocidade de germinação, indica que a dose de $0,29 \mathrm{mM} \mathrm{L}^{-1}$ de AS estimulou uma maior $(5,29)$ rapidez no processo de germinação das sementes submetidas ao tratamento controle de $0,0 \mathrm{MPa}$ (Figura 1C). Salienta-se que a aplicação da dose de $1,0 \mathrm{mM} \mathrm{L}^{-1}$ de AS atenuou o efeito do déficit hídrico até o potencial de $-0,36 \mathrm{MPa}$, decrescendo à medida que o potencial foi reduzido. Tal resposta indica que a embebição das sementes com AS tende a promover uma resposta mais rápida durante a germinação em condições de estresse. Assim, em tais condições de estresse induzido, o ácido salicílico atua nas propriedades da membrana celular, estimulando a sinalização e expressão de genes que irão proporcionar uma maior produção de compostos fenólicos, e consequentemente, promover maior expressão do vigor das sementes $[11,25]$.

Com relação ao tempo médio de germinação, a aplicação de AS reduziu o tempo necessário para que as sementes conseguissem germinar em detrimento ao tratamento sem aplicação de AS, ocorrendo o maior aumento nesse período $(7,40)$ no menor potencial osmótico de $-1,2 \mathrm{MPa}$ (Figura 1D). A velocidade média de germinação foi estimulada pela aplicação de $\mathrm{AS}$, com os maiores incrementos nas concentrações de $0,29 \mathrm{mM} \mathrm{L}^{-1}$ com 0,20 e no potencial osmótico de 0,0 MPa, diminuindo a velocidade com a redução do potencial osmótico (Figura 1E).

O prolongamento do tempo e a baixa velocidade de germinação está associado à baixa capacidade de absorção de água pela semente com a diminuição do potencial osmótico, assim as atividades metabólicas durante o processo de germinação são reduzidas, resultando no prolongamento do tempo para que as sementes consigam germinar. O osmocondicionamento das sementes proporciona alterações na cinética de absorção de água, resultando em alterações durante a fase I da germinação, retardando o aumento da taxa respiratória e início da degradação das reservas, consequentemente, tais modificações resultam no prolongamento do tempo para que ocorra a germinação da semente [26].

$\mathrm{O}$ comprimento de plântulas foi superior quando as sementes que as originaram forma submetidas a dose de $1,0 \mathrm{mM} \mathrm{L}^{-1}$ de AS e no potencial osmótico de -1,2 $\mathrm{MPa}$, com o máximo incremento de 1,84 cm (Figura 2A). Tal resposta está associada a capacidade do AS reduzir os danos nos tecidos internos da semente em condições de estresse. O AS atua como indutor do sistema antioxidante de defesa vegetal, pode estar associado a ocorrência do ajuste osmótico das sementes ao déficit hídrico, proporcionando o aumento no crescimento das plântulas A. cepa [24]. 
A

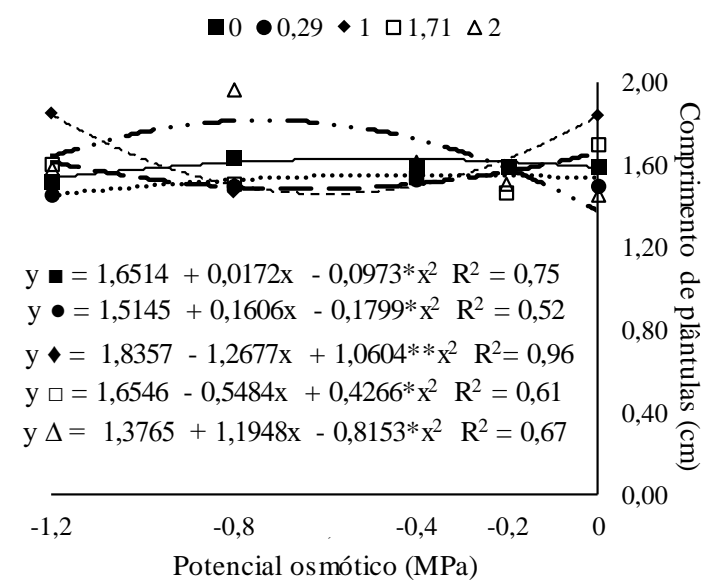

B

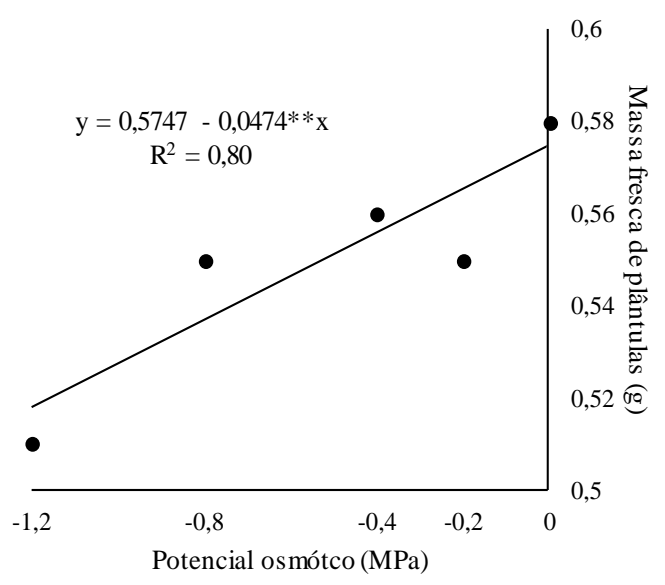

Figura 2: Comprimento $(A)$ e massa fresca de plântulas $(F)$ de C. jamacaru oriundas de sementes submetidas a diferentes potenciais osmóticos e concentrações de ácido salicílico.

Os valores de massa fresca nas plântulas de $C$. jamacaru se ajustaram ao modelo linear decrescente à medida que reduziu o potencial osmótico do substrato, atingindo perdas de $9,89 \%$ ao comparar os valores do tratamento controle com o menor potencial de -1,2 MPa (Figura 2B). A redução do vigor, avaliado pela massa fresca de plântulas ocorre pela redução da disponibilidade de água, induzindo alterações no metabolismo de enzimas que atuam na degradação dos compostos de reserva da semente, como proteínas, carboidratos e lipídeos conforme relatos de Abido e Zsombik (2018) [27].

A redução da biomassa de plântulas em função da baixa disponibilidade hídrica, é comprovado por outros autores, como Wu et al. (2019) [6] em Echinochloa crusgalli (L.) Beauv., oriundas de sementes submetidas ao estresse hídrico induzido com soluções de PEG. Assim como Rana et al. (2017) [28] em diferentes cultivares de trigo, quando constataram redução de $30 \%$ na fitomassa das plântulas originadas de sementes submetidas ao déficit hídrico. Azerêdo et al. (2016) [9], constataram redução na fitomassa de plântulas de Piptadenia moniliformis Benth., a partir do potencial de $-0,6 \mathrm{MPa}$.

\section{CONCLUSÃO}

O estresse hídrico induzido por soluções de PEG 6000 reduz a qualidade e o vigor das sementes de $C$. jamacaru; A embebição das sementes com a dose de $1,71 \mathrm{mM} \mathrm{L}^{-1}$ de AS atenua o efeito do estresse hídrico sobre a germinação de sementes de $C$. jamacaru.

\section{AGRADECIMENTOS}

À Coordenação de Aperfeiçoamento de Pessoal de Nível Superior (CAPES) pela concessão de bolsa e auxílio aos pós-graduandos no desenvolvimento da pesquisa.

\section{REFERÊNCIAS BIBLIOGRÁFICAS}

1. Silva LFCR, Valle LS, Nascimento ARC, Medeiros MFT. Cereus jamacaru DC. (Cactaceae): from 17th century naturalists to modern day scientific and technological prospecting. Acta Bot Bras. 2019 Jan;33(2):191-197, doi: 10.1590/0102-33062018abb0352.

2. Ortiz TA, Urbano MR, Takahashi LSA. Effects of water deficit and $\mathrm{pH}$ on seed germination and seedling development in Cereus jamacaru. Semina: Ciên Agra. 2019 Jul/Ago;40(4):1379-1392, doi: 10.5433/1679-0359.2019v40n4p1379. 
3. Barbosa AS, Andrade AP, Pereira Júnior LR, Bruno RLA, Medeiros RLS, Barbosa Neto MA. Estrutura populacional e espacial de Cereus jamacaru DC. em duas áreas de Caatinga do agreste da Paraíba, Brasil. Ciê Flor. 2017 Jan-Mar;27(1):315-324, doi: 10.5902/1980509826469.

4. Medeiros IU, Medeiros RA, Bortolin RH, Queiroz FM, Silbijer VN, Pflugmacher S, et al. Genotoxicity and pharmacokinetic characterization of Cereus jamacaru ethanolic extract in rats. Bios Rep. 2019 Jan;39(1):1-11, doi: 10.1042/BSR2018067.

5. Fakhfakh LM, Anjum NA, Chaieb M. Effects of temperature and water limitation on the germination of Stipagrostis ciliata seeds collected from Sidi Bouzid Governorate in Central Tunisia. J Arid Land. 2018 Jan;10(2):304-315, doi: 10.1007/s40333-018-0050-x.

6. Wu LM, Fang Y, Yang HN, Bai LY. Effects of drought-stress on seed germination and growth physiology of quinclorac-resistant Echinochloa crusgalli. PLOS ONE. 2019 Apr;14(4):e0214480, doi: 10.1371/journal.pone.0214480.

7. Marcos-Filho J. Fisiologia de sementes de plantas cultivadas. 2 ed. Londrina (PR): ABRATES; 2015. 660 p.

8. Duarte MM, Kratz D, Carvalho RLL, Nogueira AC. Influência do estresse hídrico na germinação de sementes e formação de plântulas de angico branco. Adv For Sci. 2018;5(3):375-379, doi: 10.34062/afs/.v5i3.5521.

9. Azerêdo GA, Paula RC, Valeri SV. Germinação de sementes de Piptadenia moniliformis Benth. sob estresse hídrico. Ciê Flor. 2016 Jan-Mar;26(1):193-202, doi: 10.5902/1980509821112.

10. Masetto TE, Scalon SPQ, Rezende RKS, Oba GC, Gambatti M, Patrício VS. Germinação de sementes de Dimorphandra mollis Benth.: efeito de salinidade e condicionamento osmótico. Rev Bras Biosc. 2014 Ago;12(3):127-131.

11. Silva TI, Nóbrega JS, Figueiredo FRA, Sousa LV, Ribeiro JES, Bruno RLA, Dias TJ, Albuquerque MB. Ocimum basilicum L. seeds quality as submitted to saline stress and salicylic acid. J Agric Sci. 2018 Apr;10(5):159-166, doi: 10.5539/jas.v10n5p159.

12. Nóbrega JS, Bruno, RLA, Figueiredo FRA, Silva TI, Silva RT, Lopes, KP. Effects of irrigation water salinity and salicylic acid on germination and vigor of Mesosphaerum suaveolens (L.) Kuntze. Semina: Cie Agr. 2020 Set-Out;41(5):1507-1515, doi: 10.5433/1679-0359.2020v41n5p1507.

13. Methenni K, Abdallah MB, Nouairi I, Smaoui A, Zarrouk M, Youssef NB. Salicylic acid and calcium pretreatments alleviate the toxic effect of salinity in the Oueslati olive variety. Sci Horticulturae. 2018 Mar;233:349-358, doi: 10.1016/j.scienta.2018.01.060.

14. Araújo ED, Melo AS, Rocha MS, Carneiro RF, Rocha MM. Germination and initial growth of cowpea cultivars under osmotic stress and salicylic acid. Rev Caatinga. 2018 Jan/Mar;31(1):80-89, doi: 10.1590/1983-21252018v31n110rc.

15. Villela FA, Doni-Filho L, Sequeira EL. Tabela de potenciais osmóticos em função da concentração de polietilenoglicol 6000 e da temperatura. Pesq Agrop Bras. 1991;26(11/12):1957-1968.

16. Brasil. Regras para análise de sementes. Brasília (DF): MAPA/ACS; 2009. 395 p.

17. Maguire JD. Speeds of germination-aid selection and evaluation for seedling emergence and vigor. Crop Sci. 1962 Mar;2(2):176-177, doi: 10.2135/cropsci1962.0011183X000200020033x.

18. Labouriau LG. A germinação das sementes. Washington (US): Secretaria da OEA, USA; 1983. 174 p.

19. Ferreira DF. Sisvar: a Guide for its Bootstrap procedures in multiple comparisons. Ciên Agrotec. 2014 Mar-Apr;38(2):109-112, doi: 10.1590/S1413-70542014000200001.

20. Kubala S, Garnczarska M, Wojtyla Ł, Clippe A, Kosmala A, Żmieńko A, Lutts S, Quinet M. Deciphering priming-induced improvement of rapeseed (Brassica napus L.) germination through an integrated transcriptomic and proteomic approach. Plant Sci. 2015 Feb;231:94-113, doi: 10.1016/j.plantsci.2014.11.00820.

21. Farooq M, Irfan M, Aziz T, Ahmad I, Cheema SA. Seed priming with ascorbic acid improves drought resistance of wheat. J Agro Crop Sci. 2013;199(1):12-22, doi: 10.1111/j.1439-037X.2012.00521.x.

22. Azeem M, Qasim M, Abbasi MW, Sultana YR, Adnan MY, Ali H. Sylicylic acid seed priming modulates some biochemical parametrs to improve germination and seedling growth of salt stressed wheat (Triticum aestivum L.). Pakistan J Bot. 2019;51(2):385-391, doi: 10.30848/PJB2019-2(1).

23. Nóbrega JS, Figueiredo FRA, Sousa LV, Ribeiro JES, Silva TI, Dias TJ, Albuquerque MB, Bruno RLA. Effect of salicylic acid on the physiological quality of salt-stressed Cucumis melo seeds. J Exp Agric Int. 2018 Jun;23(6):1-10, doi: 10.9734/JEAI/2018/41811.

24. Silva JESB, Paiva EP, Leite MS, Torres SB, Souza Neta ML, Guirra KS. Salicylic acid in the physiological priming of onion seeds subjected to water and salt stresses. Rev Bras Eng Agríc Amb. 2019 Dec;23(12):919-924, doi: 10.1590/1807-1929/agriambi.v23n12p919-924.

25. Tonel FR, Marini P, Bandeira JM, Morais DM, Amarante L. Salicylic acid: physiological and biochemical changes in seeds and maize seedlings subjected to salt stress. J Seed Sci. 2013;35(4):457-465, doi: $10.1590 / \mathrm{S} 2317-15372013000400007$. 
26. Lechowska, K, Kubala S, Wojtyla Ł, Nowaczyk G, Quinet M, Lutts S, Garnczarska M. New insight on water status in germinating Brassica napus seeds in relation to priming-improved germination. Int J Mol Sci. 2019 Jan;20:540, doi: 10.3390/ijms20030540.

27. Abido WAE, Zsombik L. Effect of water stress on germination of some Hungarian wheat landraces varieties. Acta Eco Sin. 2018 Dec;38(6):422-428, doi: 10.1016/j.chnaes.2018.03.004.

28. Rana MS, Hasan MA, Bahadur MM, Islam MR. Effect of polyethylene glycol induced water stress on germination and seedling growth of wheat (Triticum aestivum). The Agriculturists. 2017;15(1):81-91, doi: 10.3329/agric.v15i1.33431. 